\title{
Aspectos moleculares da anemia falciforme
}

\author{
Molecular aspects for sickle cell anemia
}

Gentil Claudino de Galiza Neto ${ }^{1}$

Maria da Silva Pitombeira²

\begin{tabular}{l|l}
\multicolumn{1}{c|}{ Unitermos } & res Um \\
Anemia falciforme & $\begin{array}{l}\text { No presente artigo abordaram-se vários aspectos relacionados à natureza molecular da } \\
\text { anemia falciforme, desordem hematológica de caráter hereditário que acomete expressivo } \\
\text { Hemoglobinopatia }\end{array}$ \\
Globina $\beta^{5}$ & $\begin{array}{l}\text { número de indivíduos em várias regiões do mundo. As pesquisas realizadas em torno desta } \\
\text { patologia da hemácia, ao longo de quase um século, a partir de 1910, cooperaram para a } \\
\text { criação de um novo e importante segmento da ciência, denominado biologia molecular. A } \\
\text { descoberta dos polimorfismos da mutação (GAT } \rightarrow \text { GTG) no gene que codifica a cadeia } \beta \text { da } \\
\text { hemoglobina, originando diferentes haplótipos da doença, permitiu um melhor e mais amplo } \\
\text { conhecimento em torno da heterogeneidade clínica nos pacientes falcêmicos. Analisando a } \\
\text { hemoglobina na sua estrutura normal e mutante, sua produção e evolução, pode-se ter um } \\
\text { entendimento mais completo da fisiopatologia desta doença e da sua complexidade clínica. }\end{array}$
\end{tabular}

\section{abstract}

The present article dealt with various aspects related to molecular nature of sickle cell disease (SCD), a heritable hematology disorder that attacks a great number of people in different regions of the world. Researches done on red cell patology, in approximately half a century, starting since 1910, cooperated to gave origin a new branch of science called molecular biology. The discovery of mutation polymorphism (GAT $\rightarrow \mathrm{GTC}$ ) in the gene that codifies $\beta$ globin chain, give origin to different illness haplotypes, permitted a better and great knowledge about the clinic heterogeneity of the patients. Analysing hemoglobin in its normal and mutation structure as well as in its productions and evolution, one can have a complete understanding of the illness phisiopathology and its clinical complexity. key words

Sickle cell anemia

Hemoglobinophatie

$\beta^{s}$ globin

Haplotypes

\section{Introdução}

No decorrer dos quase cem anos de estudos relacionados à anemia falciforme, grandes progressos foram realizados no conhecimento desta doença. Como resultado de todos estes esforços, criou-se um novo campo de estudo das ciências, a biologia molecular. De posse desta poderosa ferramenta, passou-se a desvendar a natureza genética de inúmeras patologias e/ou microorganismos potencialmente patogênicos que acometem a humanidade.

As várias formas de apresentação clínica dos pacientes portadores de anemia falciforme, em diferentes localidades do mundo, variando de formas leves, quase assintomáticas, a formas incapacitantes ou com alta taxa de mortalidade, têm sido fonte de inúmeras pesquisas há longo tempo. A substituição da base nitrogenada timina $(T)$ por adenina $(A)$, ocasionando a substituição do aminoácido ácido glutâmico por valina, na posição seis da cadeia $\beta$, é a mesma para todo paciente. A polimerização da hemoglobina $S(H b S)$ e a falcização das hemácias são extremamente bem conhecidas. As variações das condições climáticas, sociais, econômicas e de cuidados médicos contribuem para esta diversidade, mas não explicam todo o seu contexto (15).
1. Médico patologista clínico do Serviço de Hematologia da Universidade Federal do Ceará (UFC).

2. Professora titular do Departamento de Clínica Médica da Universidade Federal do Ceará.

Trabalho realizado junto ao Departamento de Clínica Médica da UFC. 
Com a primeira descrição da existência de duas mutações distintas para a $\mathrm{HbS}$, detectadas pela ação da enzima de restrição $\mathrm{Hpa}$ I no sítio de $5 \mathrm{~kb}$ a $3^{\prime}$ do gene $\beta$, estabeleceu-se o conceito de origem multicêntrica para esta doença (13). Estudos subseqüentes definiram os três principais haplótipos para a anemia falciforme: República Centro-Africana (CAR), Benin e Senegal, originados de regiões distintas do continente africano (19), e um outro haplótipo, também de origem independente, foi descrito em populações provenientes da península arábica e da Índia (14). A variabilidade genética em torno da mutação permitiu uma melhor compreensão da heterogeneidade clínica da doença, além de ter importância para o estudo antropológico (23). O presente estudo revisa os principais aspectos moleculares relacionados à anemia falciforme, esperando contribuir para um melhor e mais amplo entendimento de alguns aspectos desta doença.

\section{Hemoglobina}

A hemoglobina é a proteína respiratória presente no interior dos eritrócitos dos mamíferos que tem como principal função o transporte de oxigênio $\left(\mathrm{O}_{2}\right)$ por todo o organismo. A sua estrutura (Figura 1) é de uma proteína esferóide, globular, formada por quatro subunidades, compostas de dois pares de cadeias globínicas, polipeptídicas, sendo um par denominado de cadeias do tipo alfa (alfa- $\alpha$ e zeta- $\xi$ ) e o outro de cadeias do tipo não-alfa (beta- $\beta$, delta- $\delta$, gama- $\gamma$ e epsílon- $\varepsilon$ ). Sua estrutura é quimicamente unida a um núcleo prostético de ferro, a ferroprotoporfirina IX (heme), que detém a propriedade de receber, ligar e/ou liberar o oxigênio nos tecidos $(5,8)$. Cada cadeia polipeptídica da globina é composta por uma seqüência de aminoácidos, tendo as cadeias alfa 141 aminoácidos e as cadeias não-alfa, 146. As combinações entre as diversas cadeias de proteínas dão origem às diferentes hemoglobinas presentes nos eritrócitos desde o período embrionário (intra-uterino) até a fase adulta, produzidas no decorrer das distintas etapas do desenvolvimento humano (3).

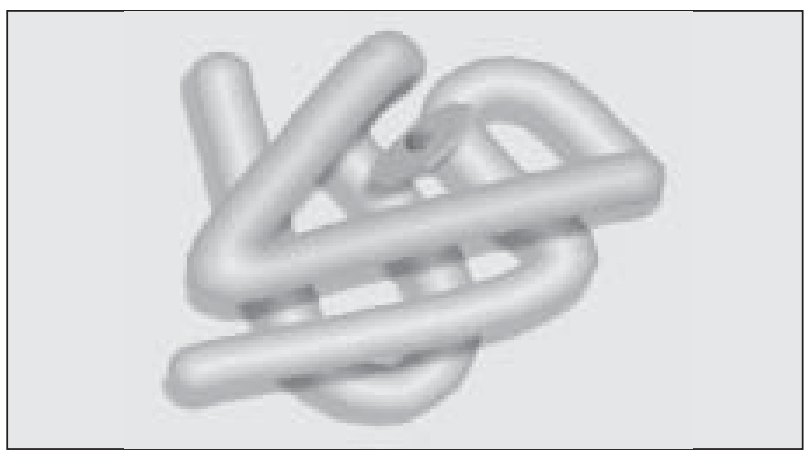

Figura 1 - Representação esquemática da cadeia $\beta$ da hemoglobina
A gênese das cadeias globínicas é regulada por agrupamentos (clusters) de genes nos cromossomos 11 e 16 (Figura 2), na ordem cronológica em que são expressos (sentido $5^{\prime} \rightarrow 3^{\prime}$ ), nos períodos embrionário, fetal e adulto, quando diferentes grupos de genes são ativados ou suprimidos e diferentes cadeias globínicas são sintetizadas independentemente. As diferentes combinações das cadeias globínicas possibilitam o surgimento de hemoglobinas distintas, e para que o tetrâmero funcional seja formado é necessário um perfeito equilíbrio na produção destas cadeias $(12,21)$.

No braço curto do cromossomo 16, em um segmento de DNA de $35 \mathrm{~kb}$, localizam-se o gene zeta ( $\xi)$, que codifica a cadeia $\xi$ globínica, dois pseudogenes, $(\psi \xi)$ e $(\psi \alpha)$, e os genes alfa $1(\alpha 1)$ e alfa $2(\alpha 2)$, que, no ser humano, estão duplicados, devendo-se este fato provavelmente à duplicação gênica no decorrer do processo evolutivo. Estes genes duplos são responsáveis pela codificação das cadeias globínicas alfa (11).

No cromossomo 11 localiza-se o complexo dos genes beta, com uma extensão superior a $60 \mathrm{~kb}$, onde se observam, no sentido $5^{\prime} \rightarrow 3^{\prime}$, os genes epsílon- $\varepsilon$, gama glicina- $\gamma^{\mathrm{C}}$, gama adenina- $\gamma^{\mathrm{A}}$, um pseudogene $(\psi \beta)$ e os genes delta- $\delta$ e beta- $\beta$ (12).

No período embrionário (Quadro), os genes ativos presentes nos eritroblastos, localizados no saco vitelino, pro-

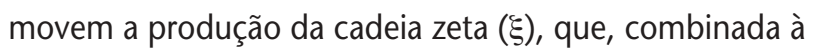
cadeia epsílon $(\varepsilon)$, forma a hemoglobina Gower-1 ( $\xi 2 \varepsilon 2)$; esta mesma cadeia zeta, combinada com a cadeia gama $(\gamma)$, forma a hemoglobina Portland $(\xi 2 \gamma 2)$; quando ocorre a produção das cadeias alfa $(\alpha)$, estas se combinam com a cadeia epsílon e formam a hemoglobina Gower-2 ( $\alpha 2 \varepsilon 2)$.

A produção das hemoglobinas embrionárias ocorre por um período de até três meses do início da evolução gestacional (18). Por grande parte da vida intra-uterina prepondera a produção da hemoglobina fetal (HbF), devido ao incremento da produção das cadeias alfa e gama e à sua combinação $(\alpha 2 \gamma 2)$, decaindo logo após os pri-

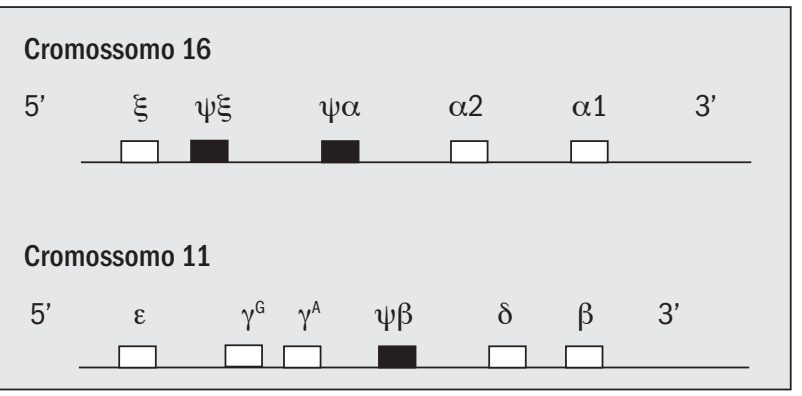

Figura 2 - Complexo do gene $\alpha$ no cromossomo 16 e complexo do gene $\beta$ no cromossomo 11 
Representação dos diferentes tipos de hemoglobina de acordo com seu principal período de produção e Quadro composição de cadeia globínica

\begin{tabular}{lcc}
$\begin{array}{l}\text { Tipo de } \\
\text { hemoglobina }\end{array}$ & $\begin{array}{c}\text { Período preponderante } \\
\text { de síntese }\end{array}$ & $\begin{array}{c}\text { Cadeias } \\
\text { globínicas }\end{array}$ \\
Gower-1 & $\begin{array}{c}\text { Embrião/até 3o mês } \\
\text { de gestação }\end{array}$ & $\xi_{2} \varepsilon_{2}$ \\
Portland & $\begin{array}{c}\text { Embrião/ até 3o mês } \\
\text { de gestação }\end{array}$ & $\xi_{2} \gamma_{2}$ \\
Gower-2 & $\begin{array}{c}\text { Embrião/ até 3o mês } \\
\text { de gestação }\end{array}$ & $\alpha_{2} \varepsilon_{2}$ \\
Hb Fetal & Feto/ até 6o mês de vida & $\alpha_{2} \gamma_{2}$ \\
$\mathrm{HbA}_{2}$ & Feto/ vida adulta & $\alpha_{2} \delta_{2}$ \\
$\mathrm{HbA}$ & Vida adulta & $\alpha_{2} \beta_{2}$ \\
\hline
\end{tabular}

meiros seis meses de vida. $O$ gene da cadeia beta $(\beta)$ globínica é expresso, com pouca intensidade, nas primeiras seis semanas de vida fetal, mas a partir deste período ocorre uma mudança (switch), quando a síntese de cadeia $\gamma$ é largamente substituída pela síntese de cadeia $\beta$, dando origem à produção da hemoglobina $\mathrm{A}(\alpha 2 / \beta 2)$. 0 mecanismo pelo qual esta mudança ocorre ainda é desconhecido, parecendo dever-se ao estado de metilação do gene, ou, ainda, ao acondicionamento cromossômico ou a outras condições que podem afetar ou influir na transcrição genética (12).

A produção das cadeias delta ( $\delta$ ) tem seu início por volta da $25^{\underline{a}}$ semana da gestação, em concentrações reduzidas, e nestes níveis permanece até o nascimento, aumentando lentamente, estabilizando-se por volta do sexto mês de vida em diante. Estas cadeias, quando ligadas às cadeias alfa $(\alpha)$, darão origem à hemoglobina $A_{2}$ $(\alpha 2 / \delta 2)(15)$. A hemoglobina A está presente nos eritrócitos após os seis meses iniciais de vida e por toda a fase adulta, sendo composta por dois pares de cadeias polipeptídicas: $\alpha 2 / \beta 2$. A distribuição proporcional das diferentes hemoglobinas nas hemácias do indivíduo a partir deste período ficam assim definidas: $\mathrm{HbA}=96 \%-98 \% ; \mathrm{HbA}_{2}=2,5 \%-3 \%$; e $\mathrm{HbF}=0 \%-1 \%(8)$.

\section{Anemia falciforme}

É uma das doenças hematológicas herdadas mais comuns em todo o mundo, atingindo expressiva parcela da popula- ção dos mais diferentes países. Esta doença surgiu nos países do centro-oeste africano, da Índia e do leste da Ásia, há cerca de 50 a 100 mil anos, entre os períodos paleolítico e mesolítico $(17,22)$. O fato que motivou a mutação do gene da hemoglobina normal $(\mathrm{HbA})$ para o gene da hemoglobina $S$ $(\mathrm{HbS})$ ainda permanece desconhecido.

A primeira descrição na literatura médica (10) de um caso clínico de anemia falciforme deveu-se à observação de hemácias alongadas e em forma de foice no esfregaço sangüíneo de Walter Clement Noel, jovem negro, originário de Granada (Índias Ocidentais), estudante do primeiro ano do Chicago College of Dental Surgery, admitido no Presbyteriam Hospital com anemia. Em 1917, Emmel observou a transformação da hemácia na sua forma original, bicôncava, para a forma de foice, in vitro, e em 1922, o termo anemia falciforme foi utilizado por Manson. Em 1927, Hanh e Gillepsie descobriram que a falcização dos eritrócitos ocorria como conseqüência da exposição das células a uma baixa tensão de $\mathrm{O}_{2}$. Em 1947, Accioly, no Brasil, pela primeira vez havia sugerido que a falciformação ocorria como conseqüência de uma herança autossômica dominante, mas só em 1949, através dos trabalhos de Neel e Beet, é que se definiu a doença somente em estado de homozigose, sendo os heterozigotos portadores assintomáticos (9).

Ainda em 1949, Linus Pauling et al. demonstraram que havia uma diferente migração eletroforética da hemoglobina de pacientes com anemia falciforme quando em comparação com a hemoglobina de indivíduos normais. Posteriormente coube a Ingram (1956) elucidar a natureza bioquímica desta doença, quando, através de um processo de fingerprint (eletroforese bidimensional associada com cromatografia), fracionou a hemoglobina e estudou os seus peptídeos. Ficou caracterizado que a anemia falciforme era ocasionada pela substituição do ácido glutâmico por valina na cadeia $\beta$ da hemoglobina, dando origem ao conceito de doença molecular. Em 1978, com os estudos de Kan e Dozy, novo impulso foi dado ao estudo da $\mathrm{HbS}$, para introdução de técnicas de biologia molecular (17).

A simples substituição pontual de uma base nitrogenada, timina por adenina (GAT $\rightarrow$ GTT), no sexto códon do éxon 1 no DNA do cromossomo 11 (Figura 3), ocasiona o surgimento de uma hemoglobina patológica (4). A troca de bases nitrogenadas no DNA, ao invés de codificar a produção (transcrição) do aminoácido ácido glutâmico, irá, a partir daí, determinar a produção do aminoácido valina, que entrará na posição 6 da seqüência de aminoácidos que compõem a cadeia $\beta$ da hemoglobina, modificando sua estrutura molecular (3). 
CROMOSSOMO 11 NORMAL

6ำ códon cadeia $\beta \rightarrow$ GAG $\rightarrow$ Ác. GLU

CROMOSSOMO 11 MUTANTE

$6^{\circ}$ códon cadeia $\beta^{S} \rightarrow$ GTG $\rightarrow$ VAL

Figura 3 - Representação esquemática da mutação gênica responsável pelo surgimento da $\mathrm{HbS}$

A aparentemente simples troca de um único aminoácido na composição da cadeia beta globínica ocasiona o surgimento de uma estrutura hemoglobínica nova, denominada hemoglobina $S$ (onde a letra $S$ deriva da palavra inglesa sickle, que em português traduz-se como foice). A hemoglobina mutante $\left(\alpha_{2} / \beta_{2}{ }_{2}\right)$ possui propriedades físico-químicas bastante diferentes da hemoglobina normal devido à perda de duas cargas elétricas por molécula de hemoglobina (por causa da perda do ácido glutâmico). Exibe ainda diferente estabilidade e solubilidade, demonstrando uma forte tendência à formação de polímeros (Figura 4) quando na sua forma de desoxiemoglobina (3). Decorre daí uma série de alterações físicoquímicas na estrutura da hemácia, ocasionando a deformação e o enrijecimento de sua membrana celular, concorrendo para o surgimento do epifenômeno patológico que é a vasoclusão. Este fenômeno é responsável por toda a seqüência de alterações estruturais e funcionais nos mais diversos órgãos e sistemas do paciente acometido (6).

A hemoglobina $S$ no estado de baixa tensão do oxigênio sofre uma modificação na sua conformação molecular devido à presença do aminoácido valina, que interage com o receptor fenilalanina ( $\beta$-85) e leucina ( $\beta-88$ ) na molécula adjacente de hemoglobina $S$ (4). Esta interação de natureza hidrofóbica desencadeia a formação de polímeros (Figura 4), compostos por 14 fibras de desoxiemoglobinas, enoveladas entre si, num processo denominado nucleação, que progride com o alongamento e alinhamento de mais fibras, criando uma estrutura multipolimérica, na forma de um eixo axial no interior da célula. Está criado assim o mecanismo de transformação da clássica forma do eritrócito em uma nova estrutura celular no formato de foice (2).

A velocidade e a extensão da formação de polímeros no interior das hemácias depende primariamente de três variáveis independentes: grau de desoxigenação, concentração intracelular de hemoglobina $S$ e presença ou ausência de hemoglobina $F(2)$. Uma das conseqüências da polimerização da HbS é a desidratação celular devida às perdas de íons potássio $\left(\mathrm{K}^{+}\right)$e de água. Os principais mecanismos destas perdas ocorrem pela ativação excessiva do canal de transporte dos íons potássio e cloro $\left(\mathrm{K}^{+} \mathrm{Cl}^{-}\right)$,

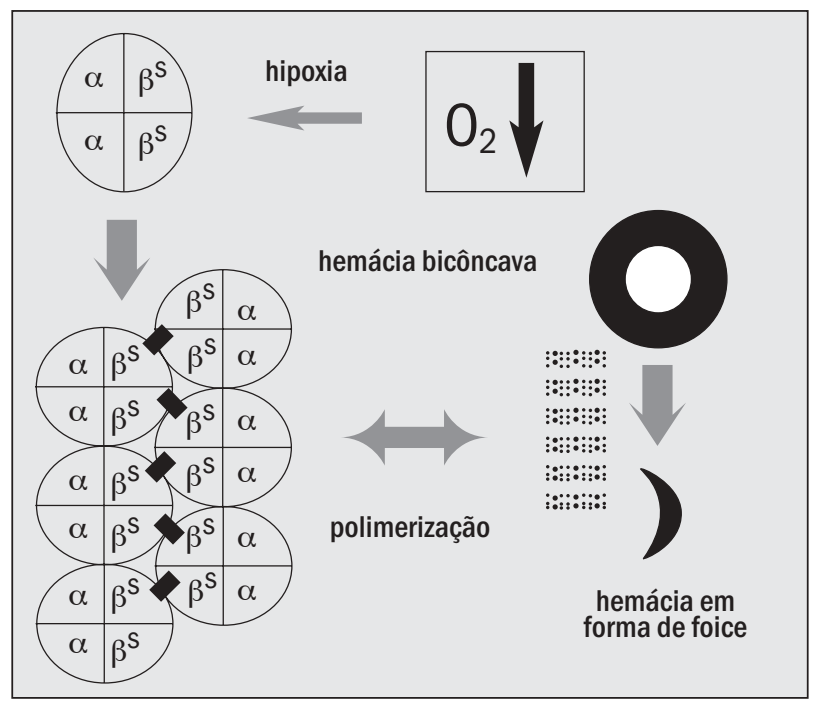

Figura 4 - Representação esquemática do processo de indução à falcização das hemácias pela polimerização da desoxiemoglobina diante da baixa concentração de oxigênio

estimulados pela acidificação, pelo edema celular (este canal está muito ativo nos reticulócitos, onde a desidratação desempenha papel importante na formação das células densas) e pelo canal de Gardos, devido ao aumento da concentração dos íons cálcio $\left(\mathrm{Ca}^{++}\right)(4)$.

Outra importante alteração da hemácia na anemia falciforme se deve à perda do seu poder deformatório, fato que lhe impossibilita transpor o menor diâmetro dos capilares da microcirculação. A perda da elasticidade da célula devese ao incremento da concentração de HbS intracelular, resultando no aumento da viscosidade no citosol, à polimerização da $\mathrm{HbS}$ e à rigidez da membrana (7). Estes fatores, associados a uma maior adesão do eritrócito falcizado ao endotélio, mediada pelo complexo de integrina $\alpha 4 \beta 1$, trombospondina, fator de von Willebrand e fibronectina, favorecem a formação de trombos na micro e na macrocirculação.

A ocorrência de vasoclusões, principalmente em pequenos vasos, representa o evento fisiopatológico determinante na origem da grande maioria dos sinais e sintomas presentes no quadro clínico dos pacientes com anemia falciforme, tais como crises álgicas; crises hemolíticas; úlceras de membros inferiores; síndrome torácica aguda; seqüestro esplênico; priapismo; necrose asséptica de fêmur; retinopatia; insuficiência renal crônica; autoesplenectomia; acidente vascular cerebral, entre outros (4).

\section{Haplótipos da mutação $\beta^{\mathrm{s}}$}

É do conhecimento geral que os indivíduos são geneticamente diferentes e que algumas das diferenças entre 
as pessoas representam mudanças genéticas patológicas. Entretanto, muito provavelmente, podem representar variações silenciosas no DNA. Tais variações, também designadas como comuns ou neutras, são denominadas de polimorfismos do DNA (1).

O tipo de variabilidade mais comum no complexo gênico das globinas alfa ou beta é aquele produzido por variações de seqüências que alteram o sítio de reconhecimento de uma enzima de restrição. Estas alterações ocorrem aproximadamente a cada cem bases ao longo do genoma. O padrão de combinação dos sítios polimórficos para qualquer cromossomo é chamado de haplótipo (1). O primeiro polimorfismo associado ao gene $\beta^{S}$ foi descrito por Kan e Dozy, em 1978, no sítio para a enzima de restrição Hpa I localizado na posição $3^{\prime}$ do gene, seguindo-se novas descrições de outros sítios (Figura 5) de polimorfismos de restrição (Mears et al., 1981; Antonarakis, 1982). Dezessete sítios polimórficos foram descritos no complexo dos genes da globina alfa e mais de duas dezenas no complexo da globina beta (1). A descoberta dos haplótipos do gene $\beta^{S}$ apresentou-se como importante elemento de análise antropológica para estudo das composições populacionais, bem como elementos de estudo clínico, os quais podem fornecer dados preditivos acerca da evolução da doença e seu nível de gravidade (20).

Cinco principais haplótipos têm sido relatados em diferentes regiões do mundo e são relacionados com países ou áreas do continente africano ou próximo a este, estando ligados a grupos populacionais específicos, recebendo as denominações de acordo com os locais de sua origem: Benin, República Centro-Africana, Senegal, Camarões, Arábia Saudita e Índia (16). Inicialmente acreditava-se que a mutação do gene $\beta^{S}$ teria uma única origem, mas estudos posteriores evidenciaram origens independentes $e$ multifocais para a doença $(19,23)$.

Estudos populacionais realizados por Lehmann e Huntsman (1974) no continente africano demonstraram importantes diferenças na intensidade e na evolução clínica da doença acometendo pessoas da mesma região africana. Análises mais aprofundadas definiram que mudanças em seqüências de bases nitrogenadas nos sítios, tais como a perda de (-) 158 bases em $5^{\prime}$ do gene $\gamma^{\mathrm{G}}$, levavam ao incremento da produção de cadeia $\gamma^{G}$, resultando no aumento da concentração de $\mathrm{Hb}$ fetal, e isto determinava uma mudança da morbidade dos pacientes (20).

Os haplótipos do gene $\beta^{S}$ têm papel importante na regulação variável da síntese da $\mathrm{Hb}$ Fetal, na relação final entre as concentrações de $\mathrm{HbS}$ e $\mathrm{HbF}$ no adulto e na taxa de redução da $\mathrm{HbF}$ durante a infância. A concentração de HbF está aumentada nos haplótipos Senegal e asiático (árabe) e decresce nos haplótipos CAR e Benin, devido a uma taxa de translação no sentido $5^{\prime} \rightarrow 3^{\prime}$ e à substituição da $\mathrm{HbF}$ por HbS mais lenta nos dois primeiros do que nos dois últimos haplótipos (20).

\section{Cromossomo 11}

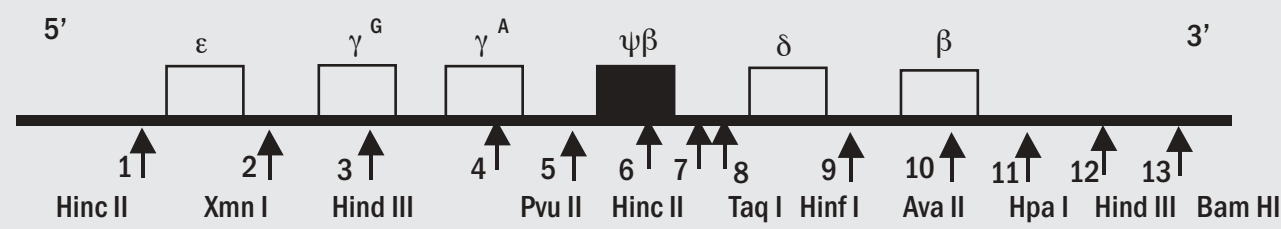

\begin{tabular}{|c|c|c|c|c|c|c|c|c|c|c|c|c|c|}
\hline Haplótipo & 1 & 2 & 3 & 4 & 5 & 6 & 7 & 8 & 9 & 10 & 11 & 12 & 13 \\
\hline CAR & - & - & + & - & + & - & - & - & - & + & + & + & + \\
\hline Benin & - & - & - & - & + & - & + & + & - & + & - & - & + \\
\hline Senegal & - & + & + & - & + & + & + & + & + & + & + & + & + \\
\hline Camarões & - & - & + & + & & - & + & & & + & + & & + \\
\hline Asiático & + & + & + & - & + & + & + & + & - & + & + & + & - \\
\hline
\end{tabular}

Figura 5 - Principais haplótipos do complexo do gene $\beta^{S}$, definidos pela ação de 13 enzimas de restrição (os Haplótipos) 


\section{Conclusão}

O estudo dos haplótipos pode ser utilizado com diferentes objetivos: para a determinação da origem unicêntrica ou multicêntrica de uma mutação, para discriminar eventos epistáticos (quando outros genes interferem na expressão fenotípica do gene mutante) e para definir o caminho de fluxo de um gene específico mutante. Quando os dados e informações estão suficientemente consolidados como no caso do cluster do gene $\beta$ mutante, então os haplótipos podem ser úteis no estudo da origem e na evolução da raça humana (16). A importância dos haplótipos da mutação $\beta^{S}$ na evolução clínica dos pacientes com anemia falciforme foi determinada através das observações quanto ao surgimento e à intensidade das complica- ções de natureza orgânica e da curva de sobrevida dos pacientes, sugerindo melhores prognósticos para os portadores dos haplótipos Senegal e árabe-indiano (Ásia) e pior evolução clínica para os pacientes portadores dos haplótipos CAR e Benin (20).

Rever os aspectos moleculares da hemoglobinopatia SS possibilita, portanto, uma melhor compreensão do surgimento da mutação do gene $\beta^{S}$ no mundo, as alterações estruturais e funcionais na hemácia dela decorrentes, bem como um entendimento mais profundo dos aspectos clínicos envolvidos no curso da evolução heterogênea da doença, tornando mais claro o entendimento da existência de diferentes intensidades de sinais e sintomas que se apresentam nos pacientes acometidos pela, aparentemente, mesma mutação gênica da anemia falciforme.

\section{Referências}

1. A ntonarakis, S.E.; Kazazian Jr., H.H.\& O rkin, S.H. D N A polymorphism and molecular pathology of the human globin gene clusters. Hum. Genet., 69: 1-14, 1985.

2. Bunn, H.F. Pathogenesis and treatment of sickle cell disease. N. Engl. J. Med., 337(11): 762-9, 1997

3. Bunn, H.F. \& Forget, B.G. Hemoglobin: molecular, genetic and clinical aspects. 1. ed.W .B. Saunders Company, 1986,690p.

4. Ballas, S.K. \& M ohandas, N . Pathophisiology of vaso-occlusion. Hematology/Oncology Clinics of North America, 10(6), 1996.

5. Dacie, J.V. \& Lewis, S.M. Pratical hematology. 6. ed. Churchill Livingstone, 1984

6. D ean, J. \& Schechter, A. N . Sickle cell anemia: molecular and cellular bases of therapeutic approaches. N. Engl. J. Med., 299(14): 752-63, 1978

7. Fabry, M.E. \& Kaul, D.K. Sickle cell vaso-occlusion. In: N agel, R.L. (eds.). Hematology/Oncology Clinics of North America Hemoglobinopathies, 5(3): 375-98, 1991.

8. Fairbanks,V.F. \& Klee, G.G. Biochemical aspects of Hematolo gy. In:Tietz, N.W. Fundamentals of clinical chemistry. 3. ed. Philadelphia:W.B. Saunders Company, 1987, v. 2, cap. 24, p. 789-824.

9. Figueiredo, M.S. Efeitos da talassemia $\alpha$ e dos haplótipos do complexo da globina $\beta$ nas alterações clínicas e laboratoriais da anemia falciforme no Brasil, São Paulo, 1993.Tese (D outorado) Escola Paulista de Medicina, Universidade Federal de São Paulo,79p.

10. Herrick, J.B. Peculiar elongated and sickle-shaped red blood corpuscles in a case of severe anemia. Arch. Intern. Med., 6:517-21, 1910

11. Higgs, D.R. et al. A review of the molecular genetics of the human $\alpha$-globin gene cluster. Blood, 73: 1081-104, 1989.

12. Hoffbrand, A.V. \& Pettit, J.E. Essential Haematology. 3. ed. London: Blackwell Science, 1993, 437p.

13. Kan, Y.M. \& Dozy, A.M. Polymorphism of DNA sequence adjacent to human $\beta$-glo bin structural gene: relationship to sickle mutation. Proc. Natl.Acad. Sci., 75:5631-5, 1978.
14. Kulozik, A.E. et al. Geographical survey of bs-globin gene haplotypes: evidence for am independent Asian origin of the sickle-cell mutation. Am. J. H um. Genet., 39: 239-44, 1986.

15. N agel, R.L.et al. Hematologically and genetically distinct forms of sickle cell anemia in A frica. N . Engl. J. M ed., 312: 880-4, 1985.

16. N agel, R.L. \& Ranney, H. M. G enetic epidemiology of structural mutations of the $\beta$-glo bin gene. Seminars in hematology, 27 : 342-59,1990.

17. N aoum, P.C . Hemoglobinopatias e talassemias. Sar vier, 1997.

18. N elson, D.A. \& Davey, F.R., Erytrocytic disorders. In: Henry, J.B. et al. (eds.) 18. ed. Clinical diagnosis \& managment by laboratory methods. Philadelphia:W .B.Saunders Company, 1991, cap. 25, p. 627-716.

19. Pagnier, J. et al. Evidence for the multicentric origin of the sickle cell hemoglo bin gene in Africa. Proc. $N$ atl. Acad. Sci., 81: 1771-3, 1984.

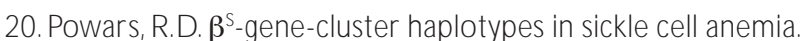
In:N A G EL, R.L. (ed.). Hematology/Oncology Clinics of N orth America - Hemoglobinopathies, 5(3): 475-93, 1991.

21. Serjent, G.R. Sickle cell disease. 2. ed. 0 xford University Press, 1992, 631p.

22.W H O,W orking G roup - Hereditary anemias: genetics basis, clinical features, diagnosis and treatment. Bull. WHO, 60:643-60, 1982.

23. Zago, M.A. 0 rigem e hetero geneidade da anemia falcifo rme. Boletim, XV(162): 3-8, 1993

Endereço para correspondência

Centil Claudino de Galiza Neto

Hemoce

Av. José Bastos 3.390

CEP 60435-160 - Fortaleza-CE

Tel.: (85) $433-4400$

e-mail: laboratorio@hru.unimedfortaleza.com.br 